\title{
Pivotal roles of prolactin and other hormones in lactogenesis and the nutritional composition of human milk
}

Yong Joo Kim, MD

Department of Pediatrics, Hanyang University College of Medicine, Seoul, Korea
Human milk contains very important nutrients that are species-specific for human infant growth and development. The benefits of human milk feeding have already been acknowledged, as has the unique importance of each nutrient contained in it. In the article titled "Components of human breast milk: from macronutrient to microbiome and microRNA" by Kim and $\mathrm{Yi}^{11}{ }^{1)}$ the authors reported that human breast milk is the most valuable nutritional source for infants and it contains microbiomes and miRNAs for growth and development. Since better nutrition is available through human milk, sufficient breast milk production is essential. Prolactin heralds the principal role in lactogenesis, but an increased understanding of the basic physiological control and interactions of diverse hormones related to lactation is recommended.

Stage I lactogenesis develops approximately 12 weeks before parturition. During this stage, levels of lactose, total proteins, and immunoglobulin significantly increase, levels of sodium and chloride decrease, and substrate for milk production gathers. ${ }^{2)}$

Stage II lactogenesis, which occurs in the postpartum period, initiates with a decrease in plasma progesterone level, increase in blood flow and oxygen and glucose uptakes, and a sharp increase in citrate concentration, a reliable marker of lactogenesis stage II. Plasma $\alpha$-lactalbumin level peaks as well.

The major changes toward "mature milk" occur over 10 days. The establishment of a mature milk supply, once called galactopoiesis, is now referred to as stage III lactogenesis. ${ }^{3)}$ Plasma prolactin levels peak during this period. Prolactin secretion increases at night; thus, nighttime breastfeeding is truly essential to promoting lactogenesis.

Prolactin is necessary for glucocorticoid stimulation of the milk protein genes in mammary epithelial cells (MECs). MECs cultured with prolactin, epidermal growth factor (EGF), and dexamethasone (glucocorticoid analog) promote the $\beta$-casein secretion pathway. In the absence of prolactin, MECs do not express $\beta$-casein well. EGF boosts $\beta$-casein expression and secretion in the presence of prolactin and dexamethasone. Dexamethasone treatment rapidly increases $\beta$-casein expression. $\left.{ }^{4}\right)$ This nutrition-enhancing effect via prolactin was proven in a human milk study of 9 puerperal women, 4 decades ago, by Healy et al.,5) who documented that prolactin is a normal constituent of human milk at high concentrations for the first 3 days after birth and that breastmilk prolactin levels correlated significantly with levels of lactose, total protein, and alpha-lactalbumin.

Prolactin synthesis and secretion are not confined to the anterior pituitary gland; rather, they also include several sites in the brain (cortex, hippocampus, amygdala, cerebellum, brain stem, and spinal cord). The placenta, amnion, decidua, and uterus also produce prolactin. Prolactin is found in the epithelial cells of the lactating mammary gland as well as breastmilk. Milk prolactin is involved in maturation of the neuroendocrine and immune systems. ${ }^{6}$

Prolactin production relies on estrogen, progesterone, glucocorticoids, insulin, the thyroid hormone, and the parathyroid hormone. Prolactin also enhances the uptake of some amino acids and glucose as well as the production of milk sugar and milk fats. ${ }^{7-9)}$ In vitro, it stimulates the synthesis of specific milk protein mRNA by binding to membrane receptors. This protein synthesis through the expression of milk protein genes is the consequence of the activation of $\mathrm{Na} / \mathrm{K}$ adenosine triphosphatase in the plasma membrane. ${ }^{8)}$

Insulin also plays an important role in milk protein synthesis at multiple levels in the murine mammary gland facilitated by milk protein transcription factors as well as glucocorticoids. ${ }^{10)}$

Prolactin attracts immunoglobulin A immunoblasts from the gut-associated lymphoid tissue for the immune system of the mammary gland.6)

There are also prolactin-inhibiting factors (PIFs). Catecholamine in the hypothalamus shows an inhibitory effect as a result of dopaminergic impulses. Drugs that upregulate the catecholamine effect can act as PIF.6) Although prolactin is necessary for milk secretion, milk volume is not directly regulated by the prolactin concentration in the plasma. ${ }^{11)}$ Therefore, diverse efforts to enhance prolactin secretion would make human milk nutritious with high levels of immunologic factors and lead to successful breastfeeding. 


\section{Conflicts of interest}

No potential conflict of interest relevant to this article was reported.

See the article "Components of human breast milk: from macronutrient to microbiome and microRNA" via https://doi. org/10.3345/cep.2020.00059.

\section{References}

1. Kim SY, Yi DY. Components of human breast milk: from macronutrient to microbiome and microRNA. Clin Exp Pediatr 2020;63:301-9.

2. Hartmann PE. Changes in the composition and yield of the mammary secretion of cows during the initiation of lactation. J Endocrinol 1973; 59:231-47.

3. Vorherr H. Hormonal and biochemical changes of pituitary and breast during pregnancy. Semin Perinatol 1979;3:193-8.

4. Kobayashi K, Oyama S, Kuki C, Tsugami Y, Matsunaga K, Suzuki T, et al.
Distinct roles of prolactin, epidermal growth factor, and glucocorticoids in $\beta$-casein secretion pathway in lactating mammary epithelial cells. Mol Cell Endocrinol 2017;440:16-24.

5. Healy DL, Rattigan S, Hartmann PE, Herington AC, Burger HG. Prolactin in human milk: correlation with lactose, total protein, and alphalactalbumin levels. Am J Physiol 1980;238:E83-6.

6. Lawrence RA, Lawrence RM, editors. Breastfeeding: a guide for medicine profession. 7th ed. Maryland Heights (MI): Mosby, 2011:69.

7. Freeman ME, Kanyicska B, Lerant A, Nagy G. Prolactin: structure, function, and regulation of secretion. Physiol Rev 2000;80:1523-631.

8. Czank C, Henderson JJ, Kent JC, Lai CT, Hartmann PE. Hormonal control of the lactation cycle. In: Hale TW, Hartmann PE, editors. Hale and Hartmann's textbook of human lactation. Amarillo (TX): Hale Publishing LP, 2007:89-111.

9. Frantz AG. Prolactin. N Engl J Med 1978;298:201-7.

10. Menzies KK, Lee HJ, Lefèvre C, Ormandy CJ, Macmillan KL, Nicholas KR. Insulin, a key regulator of hormone responsive milk protein synthesis during lactogenesis in murine mammary explants. Funct Integr Genomics 2010;10:87-95.

11. Stern JM, Reichlin S. Prolactin circadian rhythm persists throughout lactation in women. Neuroendocrinology 1990;51:31-7. 